\title{
ef1097 and ypkK encode enterococcin V583 and corynicin JK, members of a new family of antimicrobial proteins (bacteriocins) with modular structure from Gram-positive bacteria

\author{
Correspondence \\ Ralph W. Jack \\ ralph.jack@otago.ac.nz
} \\ Received 18 June 2007 \\ Accepted 24 July 2007 \\ Pearl M. Swe, ${ }^{1}$ Nicholas C. K. Heng, ${ }^{1}$ Yi-Tian Ting, ${ }^{1}$ Hayley J. Baird, ${ }^{1} \dagger$ Alan Carne, ${ }^{2}$ Andreas Tauch, ${ }^{3}$ John R. Tagg ${ }^{1}$ and Ralph W. Jack ${ }^{1}$

\footnotetext{
${ }^{1}$ Department of Microbiology and Immunology, Otago School of Medical Sciences, The University of Otago, PO Box 56, Dunedin, New Zealand 56, Dunedin, New Zealand Bielefeld, Universitätsstraße 25, 33615 Bielefeld, Germany
} \\ ${ }^{2}$ Department of Biochemistry, Otago School of Medical Sciences, The University of Otago, PO Box \\ ${ }^{3}$ Institut für Genomforschung und Systembiologie, Centrum für Biotechnologie, Universität

\begin{abstract}
Unlike the colicins, microcins and related peptide antibiotics, little is known about antibiotic proteins $\left(M_{\mathrm{r}}>10000\right)$ from Gram-positive bacteria, since only few examples have been described to date. In this study we used heterologous expression of recombinant proteins to access the $17 \mathrm{kDa}$ antibiotic protein SA-M57 from Streptococcus pyogenes, along with two proteins of unknown function identified in publicly available databases: EF1097 from Enterococcus faecalis and YpkK from Corynebacterium jeikeium. Here we show that all three are antibiotic proteins with different spectra of antimicrobial activity that kill sensitive bacteria at nanomolar concentrations. In silico structure predictions indicate that although the three proteins share little sequence similarity, they may be composed of conserved secondary structural elements: a relatively unstructured, acidic $\mathrm{N}$-terminal portion and a basic $\mathrm{C}$-terminal portion characterized by two helical elements separated by a loop structure and stabilized by an essential disulphide. Expression of individual segments as well as protein chimaeras revealed that, at least in the case of YpkK, the Cterminal portion is responsible for the killing action of the protein, whereas the role of the $\mathrm{N}$ terminal portion remains unclear. Both scnM57 and ef1097 appear to be widely distributed in Strep. pyogenes and Ent. faecalis (respectively), whereas ypkK is found only rarely amongst clinical isolates of C. jeikeium. Finally, we determined that the proteins kill sensitive bacteria without lysis, a feature that distinguishes them from known murolytic proteins.
\end{abstract}

\section{INTRODUCTION}

Bacteriocins are ribosomally synthesized, proteinaceous antibiotics produced by a variety of species of both Grampositive and Gram-negative bacteria that inhibit the growth of other bacteria. Although from a biochemical perspective they exhibit an extraordinary diversity of structure, the bacteriocins can be loosely grouped into four categories, based on their molecular mass and whether the producing organism is Gram-positive or Gramnegative. For example, a number of species of the Enterobacteriaceae produce large, modular, antimicrobial proteins $\left(M_{\mathrm{r}}>10000\right)$ known as colicins (Cascales et al., 2007), whilst others produce relatively lower molecular

tPresent address: AgResearch Ltd, Department of Biochemistry, Otago School of Medical Sciences, The University of Otago, PO Box 56, Dunedin, New Zealand. mass antimicrobial peptides $\left(M_{\mathrm{r}}<10000\right)$ termed microcins (Heng \& Jack, 2006). Similarly, a veritable plethora of modified and unmodified peptide bacteriocins $\left(M_{\mathrm{r}}<10000\right)$ from Gram-positive bacteria have also been described, particularly those elaborated by the lactic acid bacteria (Bonelli et al., 2006; Nes et al., 2006; Heng et al., 2007). In recent years considerable research interest has focussed on the low molecular mass polypeptides from both Gram-positive and Gram-negative bacteria, in part because of their potential in pharmaceutical and nutraceutical applications (Cleveland et al., 2001; Ross et al., 2002; Gillor et al., 2004; Kirkup, 2006).

Despite the amount of research directed at the peptide bacteriocins of Gram-positive bacteria, microcins and colicins, surprisingly little is known about the higher molecular mass $\left(M_{\mathrm{r}}>10000\right)$ bacteriocins from Gram-positive bacteria. 
Several bacteriocins that have proven to be cell-wallhydrolysing (murolytic) enzymes, such as lysostaphin, zoocin A and stellalysin, have been reported from Grampositive bacteria (Schindler \& Schuhardt, 1964; Simmonds et al., 1996; Heng et al., 2006b). Historically, staphylococcin 1580 from Staphylococcus epidermidis (Jetten \& Vogels, 1972a, b; Jetten et al., 1972) was reported to be a bacteriocin with a subunit molecular mass of $\sim 20 \mathrm{kDa}$ that formed multimeric structures of $300-400 \mathrm{kDa}$ in conjunction with carbohydrate and lipid. However, more recent reisolation of the inhibitory agent revealed the antimicrobial activity to be epidermin, a peptide bacteriocin (2164.6 Da) belonging to the lantibiotic subgroup, which co-purified with the higher molecular mass species (Sahl, 1994). Two additional high molecular mass bacteriocins from Grampositive bacteria have been reported: helveticin J from Lactobacillus helveticus 481 (Joerger \& Klaenhammer, 1986, $1990)$ and a potentially related, unnamed compound from Lb. helveticus CNRZ450 (Thompson et al., 1996). The former was suggested to have a monomeric molecular mass of $37 \mathrm{kDa}$ and to form aggregates of $>300 \mathrm{kDa}$, whereas the latter was reported to be a bacteriocin with multimeric molecular mass of $30-50 \mathrm{kDa}$ and potentially composed of $\sim 17 \mathrm{kDa}$ monomers. Helveticin $\mathrm{J}$ is active against other lactic acid bacteria such as lactobacilli and lactococci, is chromosomally encoded and was shown to be inactivated by proteolytic digestion and heat (Joerger \& Klaenhammer, 1986, 1990), features consistent with its size and proteinaceous nature.

More recently, we have described the $17 \mathrm{kDa}$ bacteriocin streptococcin A-M57 from Streptococcus pyogenes, identified during the sequencing of a novel plasmid (pDN571) isolated from a prototype M-57 strain (Heng et al., 2004) and the detailed characterization of dysgalacticin, a $21.5 \mathrm{kDa}$ anionic, plasmid-encoded bacteriocin from Streptococcus dysgalactiae subsp. equisimilis (Heng et al., 2006). In the former study, we also identified two further putative proteins that were recognized during interrogation of public databases and were predicted to have both sequence and structural similarity to streptococcin A-M57: EF1097 from Enterococcus faecalis (accession no. AAO80897; Paulsen et al., 2003) and YpkK from Corynebacterium jeikeium (accession no. AAL85945; Tauch et al., 2004). Interestingly, these proteins share no similarity with those described above, indicating that they may represent a novel family of antibiotic proteins from Gram-positive bacteria. In this study, we report the expression of these proteins in Escherichia coli and present evidence that EF1097 and YpkK are antimicrobial proteins with structural similarity to, but different antimicrobial spectra from, streptococcin A-M57. Moreover, we show that the C-terminal portion of YpkK is the essential killing moiety.

\section{METHODS}

Bacterial strains, culture media and culture conditions. Escherichia coli DH5 $\alpha$ (Hanahan, 1983) was the host for all expression studies and was propagated aerobically at $37^{\circ} \mathrm{C}$, either in LB broth or on LB agar (Sambrook \& Russell, 2001); when required ampicillin was added at $100 \mu \mathrm{g} \mathrm{ml}^{-1}$. The bacterial strains used in spectrum of activity studies (Table 3 ) were routinely propagated aerobically at $37{ }^{\circ} \mathrm{C}$ on Columbia Agar Base (Becton Dickinson) containing $5 \%$ $(\mathrm{v} / \mathrm{v})$ whole human blood or in Todd-Hewitt broth (Difco) at the same temperature. Bacterial strains were maintained as frozen stock cultures stored at $-80{ }^{\circ} \mathrm{C}$ in Todd-Hewitt broth containing $20 \%$ $(\mathrm{v} / \mathrm{v})$ glycerol (Sigma-Aldrich).

Assessment of biological activity. The biological activity of various protein preparations was determined against the bacterial indicator strains, either in a qualitative 'spot assay' or in a quantitative minimum inhibitory concentration (MIC) determination. In the former a $5 \mathrm{mg} \mathrm{ml}^{-1}$ protein solution for spectra studies, or a $1 \mathrm{mg}$ $\mathrm{ml}^{-1}$ solution for the YpkK domain constructs, was sterilized by filtration using a $0.22 \mu \mathrm{m}$ low-protein-binding PTFE syringe-driven filtration membrane (Millex-LG, Millipore), and $10 \mu$ l aliquots were applied to blood agar plates and allowed to dry in; the plates were then seeded with the indicator bacterium under test and incubated aerobically at $37{ }^{\circ} \mathrm{C}$ for $\sim 18 \mathrm{~h}$. A zone of inhibition of the indicator lawn with a diameter of at least $5 \mathrm{~mm}$ was arbitrarily defined as positive inhibition. The quantitative MIC determination was carried out essentially as previously described (Staubitz et al., 2001) except that Tryptic Soy Broth (Difco) was used to support bacterial growth, the microtitre plates were not shaken and either Micrococcus luteus T18 or Lactococcus lactis T-21 (Tagg \& Bannister, 1979) was used to quantify the biological activity. The ability of the proteins to lyse either live or dead target bacteria using agar-immobilized or liquid culture-based assays was assessed essentially as previously described (Wirawan et al., 2007).

Recombinant DNA techniques, construction of recombinant expression systems and bioinformatic analyses. PCR amplicons and plasmids from E. coli were purified using appropriate kits (Qiagen) according to the manufacturer's recommendations. Protocols for molecular biological techniques (cloning, plasmid transformation, etc.) were conducted as described by Sambrook \& Russell (2001). The high-fidelity enzyme Platinum $p f x$ DNA polymerase (Invitrogen) was used in accordance with the manufacturer's protocols in all PCR experiments; all primers (Table 1) were purchased from Invitrogen. DNA sequence analyses were carried out by the Allan Wilson Centre Genome Service (Palmerston North, New Zealand). Similarity searches used appropriate BLAST algorithms (Altschul et al., 1997; Schäffer et al., 2001), alignments were accomplished using CLUSTAL w (http://www.ebi.ac.uk/clustalw/; Chenna et al., 2003), and assembly and basic analyses of sequence data were carried out using GeneJockey II (Biosoft). In silico predictions of secretion signal peptides were accomplished using SignalP 3.0 (Vullo \& Frasconi, 2004), whilst structural predictions were made using the suite of programs available on the Expert Protein Analysis System (ExPASy) proteomics server (http://expasy.org; Gasteiger et al., 2003) or the PredictProtein server (http://predictprotein.org; Rost et al., 2004).

The principal features of the pQE80L-based expression system (Qiagen) used for all recombinant proteins produced in this study has been previously described (Heng et al., 2004, 2006). In order to express full-length constructs, appropriate forward and reverse primers were used to amplify the correct product from the respective genomic DNA template, and the products were purified, digested, cloned into pQE80L and transformed into E. coli DH5 $\alpha$. Plasmids were recovered from appropriate transformants, nucleotide sequenced to confirm their identity, and those with the correct inserts were used further as template in PCR for the generation of Nand C-terminal segment constructs and the expression of protein chimaeras. In order to construct the former, N-terminal segments 
Table 1. Sequences and characteristics of the primers used in the construction of various recombinant protein expression systems

\begin{tabular}{|c|c|}
\hline Primer & Sequence $\left(5^{\prime}-3^{\prime}\right)$ \\
\hline \multicolumn{2}{|c|}{ Full-length constructs ${ }^{\star}$} \\
\hline SAM57-F1 & ACCAGGATCCGGCAGCATTGAAGGCCGTAAGTAGTAGCTGACGAAAAAACTTC \\
\hline SAM57-R1 & CCCAAGCTTTTAGAAGTTGATTCCGCATTG \\
\hline EF1097-F1 & ACCAGGATCCGGCAGCATTGAAGGCCGTTCTGACCAGCTAGAGGATTCAGAAGTTGAGGC \\
\hline EF1097-R1 & CTATCGAAGCTTACACAAAAGCGATGATAAAACT \\
\hline YpkK-F1 & ACCAGGATCCGGCAGCATTGAAGGCCGTGCAGAGACTCCTGCCGCTGTCGAATCTGCA \\
\hline YpkK-R1 & ATCCTCCAAGCTTACGTCCTTCTTGTTCTG \\
\hline \multicolumn{2}{|c|}{ N-terminal segments $\dagger$} \\
\hline QIAF & CGGATAACAATTTCACACAG \\
\hline ScnM57-R2 & CCCAAGCTTTTAAACTTTATACATGATTGC \\
\hline EF1097-R2 & CCCAAGCTTTTATACTGTTGAAGCATCAGA \\
\hline YpkK-R2 & CCCAAGCTTTTACACGGACTGACCGGTGGC \\
\hline \multicolumn{2}{|c|}{ C-terminal segments $\ddagger$} \\
\hline QIAR & ATTGGGATATATCAACGGTGG \\
\hline ScnM57-F2 & ACCAGGATCCGGCAGCATTGAAGGCCGTGTTGATTGGGGCGCACTAGGAAAC \\
\hline EF1097-F2 & ACCAGGATCCGGCAGCATTGAAGGCCGTGTAGTTCAAGCACGTTTTAATTGG \\
\hline YpkK-F2 & ACCAGGATCCGGCAGCATTGAAGGCCGTGTGTCCACGCGCGGGGCTGGAACA \\
\hline \multicolumn{2}{|l|}{ Chimaeras $\S$} \\
\hline ScnM57-SalF & ATGTATAAAGTCGACTGGGGCGCACTAGGAAAC \\
\hline ScnM57-SalR & GCCCCAATCGTCGACTTTATACATGATTGCATTTTC \\
\hline EF1097-SalF & GCTTCAACAGTCGACCAAGCACGTTTTAATTGG \\
\hline EF1097-SalR & TGCTTGAACGTCGACTGTTGAAGCATCAGAAATATT \\
\hline YpkK-SalF & CAGTCCGTGTCGACGCGCGGGGCTGGAACA \\
\hline YpkK-SalR & GCGCGTGGAGTCGACGGACTGACCGGTGGCAGAATT \\
\hline \multicolumn{2}{|c|}{ Screening primers } \\
\hline EF1097-F3 & GGCGATGGCATTACTAATGACATTAGG \\
\hline EF1097-R3 & CTTAGCCCACATTGAACTGCCCATAAAGC \\
\hline YpkK-F3 & CGCTGTCGAATCTGCAGGAA \\
\hline YpkK-R3 & GACGCCTTGCTTAGCTAGGT \\
\hline
\end{tabular}

${ }^{\star}$ The engineered BamHI restriction site is underlined, the engineered HindIII restriction site is double underlined and the engineered flexi-linker/ factor Xa cleavage site (GSGSIEGR) is in bold.

$\dagger$ The engineered HindIII restriction site is underlined.

$¥$ The engineered BamHI restriction site is underlined and the engineered flexi-linker/factor Xa cleavage site (GSGSIEGR) is in bold. §The engineered SalI restriction site is underlined.

were amplified using QIAF and appropriate reverse primers, whereas C-terminal segments were amplified using appropriate forward primers and QIAR; in each case the products were purified, digested with BamHI and HindIII, cloned into pQE80L and transformed into E. coli $\mathrm{DH} 5 \alpha$ and appropriate transformants were selected and characterized prior to expression of the protein. In order to construct expression systems for chimaeras, the appropriate $\mathrm{N}$-terminal segment was amplified by PCR using forward primers for the fulllength constructs and an appropriate reverse primer incorporating a SalI restriction site, whereas the C-terminal segments were amplified using the appropriate forward primer incorporating a SalI restriction site and QIAR. Purified PCR products were restricted with SalI and ligated. The ligation mix was then used as template in a PCR amplification carried out using a forward primer appropriate for fulllength amplification of the N-terminal segment (incorporating a BamHI restriction site) and a reverse primer appropriate for amplification of the C-terminal segment (incorporating a HindIII restriction site). The product was purified, restricted with $\mathrm{BamHI}$ and HindIII, ligated into PQE80L and then transformed into E. coli DH5 $\alpha$. The identity of the inserts obtained was verified by sequencing of selected transformants.
Expression, purification, modification and bioanalytical characterization of recombinant proteins. The expression and purification of all recombinant proteins, as well as the reductive alkylation of selected proteins, was carried out as previously described (Jack et al., 1996; Heng et al., 2004, 2006). SDS-PAGE analyses were carried out by electrophoretic separation on precast $16 \%$ Tris-Tricine gels (Invitrogen) using the manufacturer's apparatus, chemicals and protocols, and protein bands were visualized with Coomassie brilliant blue G250 (Bio-Rad). Bioanalytical characterization of recombinant proteins involved mass spectrometry and, where necessary, $\mathrm{N}$ terminal amino acid sequence analysis; this work was undertaken by the Centre for Protein Research (University of Otago).

Assessment of the distribution of ef1097 and ypkK. Various clinical isolates of Enterococcus faecalis and Enterococcus faecium from our laboratory collection were used in colony PCR incorporating the primer pair EF1097-F3 and EF1097-R3 to detect ef1097. In order to detect $y p k K$, PCR were performed on clinical isolates of the nosocomial pathogen C. jeikeium obtained from the University Hospitals, Leuven (Belgium), and at the Universite Louis Pasteur, Strasbourg (France), with the primer pair YpkK-F3/YpkK-R3 
Table 2. Description of the recombinant proteins constructed in this study

\begin{tabular}{|ll|}
\hline Recombinant protein & \multicolumn{1}{c}{ Description } \\
\hline Streptococcin A-M57 (SA-M57) & ScnM57† [Lys28-Phe179] (i.e. the 152 amino acid mature protein) \\
Enterococcin V583 & EF1097 [Ser35-Ser170] (i.e. the 136 amino acid mature protein) \\
Corynicin JK & YpkK§ [Ala28-Trp164] (i.e. the 137 amino acid mature protein) \\
ScnM57[Lys28-Lys105] & N-terminal segment of SA-M57 \\
EF1097[Ser35-Val93] & N-terminal segment of enterococcin V583 \\
YpkK[Ala28-Ser87] & N-terminal segment of corynicin JK \\
ScnM57[Val106-Phe179] & C-terminal segment of SA-M57 \\
EF1097[Val94-Ser170] & C-terminal segment of enterococcin V583 \\
YpkK[Val88-Trp164] & C-terminal segment of corynicin JK \\
ScnM57[Lys28-Lys105]/EF1097[Val94-Ser170] & Chimaera (SA-M57 N-terminal segment fused to enterococcin V583 C-terminal \\
& segment) \\
ScnM57[Lys28-Lys105]/YpkK[Val88-Trp164] & Chimaera (SA-M57 N-terminal segment fused to corynicin JK C-terminal \\
& segment) \\
EF1097[Ser35-Val93]/SA-M57[Val106-Phe179] & Chimaera (enterococcin V583 N-terminal segment fused to SA-M57 C-terminal \\
& segment) \\
EF1097[Ser35-Val93]/YpkK[Val88-Trp164] & Chimaera (enterococcin V583 N-terminal segment fused to corynicin JK \\
& C-terminal segment) \\
YpkK[Ala28-Ser87]/SA-M57[Val106-Phe179] & Chimaera (corynicin JK N-terminal segment fused to SA-M57 C-terminal \\
& segment) \\
YpkK[Ala28-Ser87]/EF1097[Val94-Ser170] & Chimaera (corynicin JK N-terminal segment fused to enterococcin V583 \\
& C-terminal segment) \\
&
\end{tabular}

${ }^{\star}$ Reported in a previous study (Heng et al., 2004).

$\dagger$ GenBank accession no. AAT72798.

\$GenBank accession no. NP_814827.

§GenBank accession no. AAL85945.

(Table 1), obtained from Operon Biotechnologies (Cologne, Germany). In each case, PCR amplification was carried out using Taq DNA polymerase according to standard procedures, and products generated were separated by electrophoresis on $1 \%$ agarose gels and visualized by transillumination following staining with ethidium bromide. E. coli $\mathrm{DH} 5 \alpha$ with and without pQE80Lenterococcin V583 served as controls for ef1097 amplifications, whilst purified plasmid DNA of pB85766 and pK64 (Tauch et al., 2004) served as controls for the identification of $y p k K$.

\section{RESULTS AND DISCUSSION}

\section{The hypothetical proteins EF1097 and YpkK are precursors of two novel protein antibiotics}

We have previously shown that recombinant expression of antibacterial proteins is a practical route to obtaining proteins in sufficient quantities for further study, as well as in clearly demonstrating that the antibiotic protein is solely responsible for the activity observed (Heng et al., 2006a, b). In the present study the predicted mature forms of ScnM57 (i.e. ScnM57[Lys28-Phe179] or SA-M57), EF1097 (i.e. EF1097[Ser35-Ser170]) and YpkK (i.e. YpkK[Ala28Trp164]; Table 2) were individually expressed as recombinant proteins in E. coli, purified and characterized to confirm their identity. All three recombinant proteins had demonstrable antimicrobial activity against a variety of bacterial strains (Table 3) with MICs against Lactococcus lactis of $\sim 64 \mathrm{nM}, 4 \mathrm{nM}$ and $2 \mathrm{nM}$ for SA-M57, EF1097 and YpkK, respectively. Interestingly, some bacterial strains such as Micrococcus luteus, Lc. lactis and several species of listeriae appeared susceptible to all three antibiotics, whilst other indicators were targeted in a highly specific manner. Still others, for example all staphylococcal species tested, were insensitive to the effects of the three antibiotics. Similarly, no antimicrobial activity could be detected when SA-M57, EF1097[Ser35-Ser170] or YpkK[Ala28-Trp164] were tested against a variety of Gram-negative bacteria (not shown). Since their current names reflect their unknown status, as well as the observation that the mature, biologically active proteins are not the primary translation product of their respective gene but are revealed only after cleavage of a leader peptide, we suggest that EF1097[Ser35Ser170]) be renamed enterococcin V583 and YpkK[Ala28Trp164] be renamed corynicin JK to adequately reflect their bacteriocinogenic nature.

In silico alignments of the respective sequences of SA-M57, enterococcin V583 and corynicin JK (Fig. 1) indicate that the polypeptides share little similarity in the $\mathrm{N}$-terminal half of their sequences and only minimal similarity in the C-terminal portion. However, it has previously been noted that they do contain conserved predicted secondary structural similarity in the latter portion (Heng et al., 
Table 3. Spectrum of antimicrobial activity of purified, recombinant SA-M57, EF1097 and YpkK

\begin{tabular}{|c|c|c|c|c|}
\hline \multirow[t]{3}{*}{ Bacterium } & \multirow{3}{*}{$\begin{array}{l}\text { No. of } \\
\text { strains } \\
\text { tested: }\end{array}$} & \multicolumn{3}{|c|}{$\begin{array}{c}\text { No. of strains sensitive to } \\
\text { recombinant: }\end{array}$} \\
\hline & & \multicolumn{3}{|c|}{ SA-M57 Enterococcin Corynicin } \\
\hline & & & V583 & JK \\
\hline $\begin{array}{l}\text { Corynebacterium } \\
\text { diphtheriae }\end{array}$ & 1 & 0 & 0 & 1 \\
\hline C. ulcerans & 1 & 0 & 0 & 1 \\
\hline Enterococcus faecalis & 11 & 0 & 11 & 0 \\
\hline Ent. hirae & 2 & 1 & 2 & 0 \\
\hline $\begin{array}{l}\text { Lactobacillus } \\
\text { acidophilus }\end{array}$ & 1 & 0 & 1 & 1 \\
\hline Lb. casei & 1 & 0 & 1 & 0 \\
\hline Lactococcus lactis & 2 & 2 & 2 & 2 \\
\hline Listeria grayi & 1 & 1 & 1 & 1 \\
\hline Lis. innocua & 1 & 0 & 1 & 1 \\
\hline Lis. ivanovii & 1 & 1 & 1 & 0 \\
\hline Lis. monocytogenes & 3 & 1 & 3 & 1 \\
\hline Lis. murrayi & 1 & 1 & 1 & 1 \\
\hline Lis. seeligeri & 1 & 1 & 1 & 1 \\
\hline Lis. welshimeri & 1 & 0 & 1 & 0 \\
\hline Micrococcus luteus & 2 & 2 & 2 & 2 \\
\hline Staphylococcus aureus & 8 & 0 & 0 & 0 \\
\hline Staph. cohnii & 1 & 0 & 0 & 0 \\
\hline Staph. epidermidis & 1 & 0 & 0 & 0 \\
\hline Staph. hominis & 1 & 0 & 0 & 0 \\
\hline Staph. saprophyticus & 1 & 0 & 0 & 0 \\
\hline Staph. simulans & 1 & 0 & 0 & 0 \\
\hline Staph. warneri & 1 & 0 & 0 & 0 \\
\hline Stomatococcus spp. & 3 & 0 & 0 & 0 \\
\hline $\begin{array}{c}\text { Streptococcus } \\
\text { constellatus }\end{array}$ & 2 & 0 & 0 & 0 \\
\hline Strep. dysgalactiae & 2 & 0 & 1 & 0 \\
\hline Strep. equisimilis & 1 & 0 & 0 & 0 \\
\hline Strep. gordonii & 3 & 0 & 3 & 0 \\
\hline Strep. mitis & 3 & 0 & 3 & 0 \\
\hline Strep. mutans & 2 & 0 & 0 & 0 \\
\hline Strep. oralis & 1 & 0 & 1 & 0 \\
\hline Strep. pyogenes & 8 & 0 & 8 & 0 \\
\hline Strep. salivarius & 13 & 0 & 0 & 0 \\
\hline Strep. sanguinis & 3 & 0 & 3 & 0 \\
\hline Strep. uberis & 1 & 0 & 0 & 0 \\
\hline
\end{tabular}

2004). Moreover, whilst the full-length SA-M57, enterococcin V583 and corynicin JK have predicted acidic pI values of $4.8,4.9$ and 5.4, respectively, the $\mathrm{N}$-terminal portions of each appear to be more acidic (pI 4.1, 3.8 and 4.0 , respectively) whilst the individual C-terminal segments are basic (pI 9.6, 10.0 and 9.8, respectively). These observations lead us to hypothesize that such antibiotic proteins may be composed of two portions: N-terminal segments with diverse structure and sequences responsible for targeting the diverse ranges of susceptible bacteria, and C-terminal portions with highly conserved secondary structure (but not primary structure) responsible for the killing action of the proteins.

\section{SA-M57, enterococcin V583 and corynicin JK contain an essential disulphide bond}

One of the few highly conserved features of the C-terminal portions of all three antibiotics is a pair of Cys residues (Fig. 1) that are predicted in silico to form a disulphide. We have previously shown that the related antibiotic protein dysgalacticin contains a disulphide that is essential for biological activity (Heng et al., 2006). In the present study, differential $S$-alkylation in the presence or absence of a reducing agent demonstrated that (i) recombinant SAM57, enterococcin V583 and corynicin JK each contain a single disulphide bond and (ii) this bond is essential for biological activity (Table 4). This result further demonstrates the structural similarities conserved amongst the Cterminal portions of all members of this novel family of antimicrobial proteins and also supports the hypothesis that the C-terminal portion is essential for killing activity. In silico structure predictions for all three polypeptides indicate that, whilst the $\mathrm{N}$-terminal segment is relatively unstructured, the C-terminal region may be composed of two helical elements, separated by a flexible loop region (Heng et al., 2004, 2006). Since the conserved Cys residues are located immediately before the first and immediately after the second putative helix, it seems reasonable to assume that the covalent bridge formed by the disulphide holds the helices parallel to one another and stabilizes the overall conformation of this region.

\section{Dissection of the molecular architecture of SA-M57, enterococcin V583 and corynicin JK}

In order to gain insight into the molecular architecture of these antibiotic proteins, we expressed the respective $\mathrm{N}$ terminal portions of each antibiotic in the same manner as the mature full-length proteins (Table 2). None of the purified recombinant $\mathrm{N}$-terminal segments showed antibacterial activity at any concentration tested. In addition, we observed neither agonistic nor antagonistic effects when susceptible cells were either pre- or concomitantly treated with the N-terminal segment and its cognate full-length polypeptide. This latter result may indicate that the $\mathrm{N}$ terminal portion is not (solely) responsible for target specificity.

By contrast, attempts to express either ScnM57[Val106Phe179] or EF1097[Val94-Ser170] were unsuccessful; the reasons for this were not further investigated, but appeared to involve toxicity to the heterologous host as it failed to thrive after induction. We did however successfully express, isolate and characterize the C-terminal portion of YpkK. Interestingly, YpkK[Val88-Trp164] was biologically active in a spot assay (Fig. 2A) and had a MIC against M. luteus of $\sim 72 \mathrm{nM}$, a value only sixfold less than that for corynicin JK (MIC $12 \mathrm{nM}$ ). In a further experiment, approximately equal amounts of purified, recombinant 


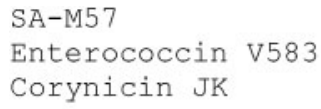

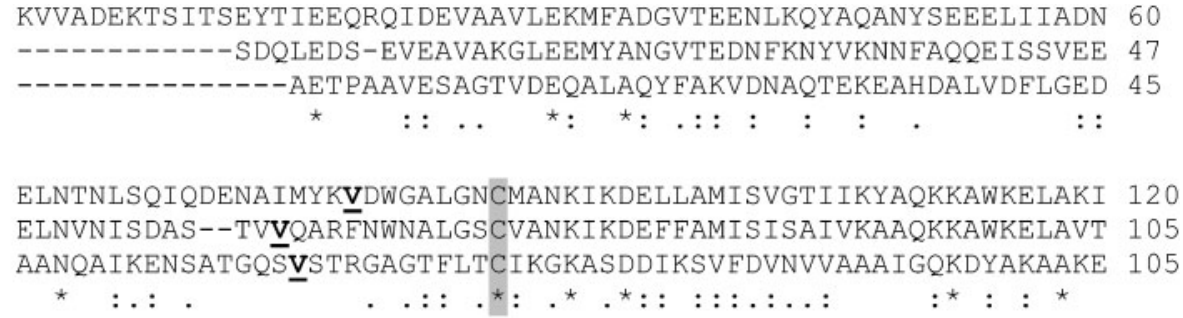

Fig. 1. CLUSTAL W-generated (Chenna et al., 2003), gapped alignment of SA-M57, enterococcin V583 and corynicin JK. The conserved cysteines involved in disulphide formation are highlighted and the arbitrarily assigned first amino acid (Val) of the expressed C-terminal portions is shown in bold and underlined; * indicates identical amino acids; : indicates functionally conserved amino acids; . indicates partially conserved residues.

YpkK[Ala28-Ser87] and YpkK[Val88-Trp164] were mixed, but this had neither an agonistic nor an antagonistic effect on the biological activity of the mixture. Similarly, YpkK[Ala28-Ser87] was neither agonistic nor antagonistic to corynicin JK when the two were mixed in approximately equal proportions. Surprisingly, YpkK[Val88-Trp164] also showed the same spectrum of activity as corynicin JK (not shown), indicating that the determinants of target specificity lie, at least partially, within this portion of the polypeptide and not the $\mathrm{N}$-terminal region as hypothesized. The reduced antimicrobial activity of YpkK[Val88Trp164] compared with corynicin JK also indicates that the $\mathrm{N}$-terminal portion is at least indirectly involved in biological activity. Since the N- and C-terminal segments have opposite (and therefore attractive) pI, it is possible that the N-terminal segment interacts with and stabilizes the C-terminal portion or that it interacts with a possible 'receptor', thereby better localizing the C-terminal region to its target.
In order to gain further understanding of the molecular architecture of these antibiotic proteins, we also constructed expression systems for six chimaeras incorporating each of the three N-terminal portions fused to each possible Cterminal segment (Table 2). These experiments were based on the premise that if target specificity is defined by the $\mathrm{N}$ terminal portion, then swapping potential 'domains' might alter the spectrum of activity of a given C-terminal segment and further clarify the role of the individual N-terminal portions. Surprisingly, only two of these recombinant chimaeras, namely ScnM57[Lys28-Lys105]/EF1097[Val94Ser170] and ScnM57[Lys28-Lys105]/YpkK[Val88-Trp164], were expressed in the heterologous host as judged by SDSPAGE. Again, the reasons for the failure of the remaining four to express in E. coli were not further investigated, but in this case it did not appear to involve host toxicity as the host grew as well as controls expressing full-length constructs during the expression phase. Both expressed chimaeras were isolated and analytically characterized to confirm their

Table 4. Effect on mass and antimicrobial activity of exposure of recombinant SAM-57, EF1097 and YpkK to the S-alkylating agent 4 -vinylpyridine, with or without prior reduction by 2 -mercaptoethanol

\begin{tabular}{|c|c|c|c|c|c|c|}
\hline Treatment & \multicolumn{2}{|c|}{ SA-M57 } & \multicolumn{2}{|c|}{ Enterococcin V583 } & \multicolumn{2}{|c|}{ Corynicin JK } \\
\hline 4-Vinylpyridine & $16879 \pm 4$ & 64 & $14833 \pm 5$ & 4 & $14439 \pm 7$ & 2 \\
\hline $\begin{array}{c}\text { 2-Mercaptoethanol/ } \\
\text { 4-vinylpyridine } \dagger\end{array}$ & $17085 \pm 4$ & $>1024$ & $15044 \pm 6$ & $>1024$ & $14649 \pm 7$ & $>1024$ \\
\hline
\end{tabular}

${ }^{*}$ MIC was determined against Lc. lactis strain T-21 (Tagg \& Bannister, 1979).

$\dagger$ Samples were treated with 2-mercaptoethanol for $1 \mathrm{~h}$ at room temperature prior to $S$-alkylation. 
(A)

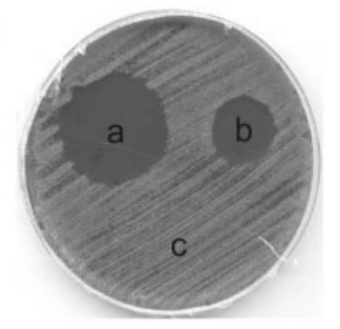

(B)

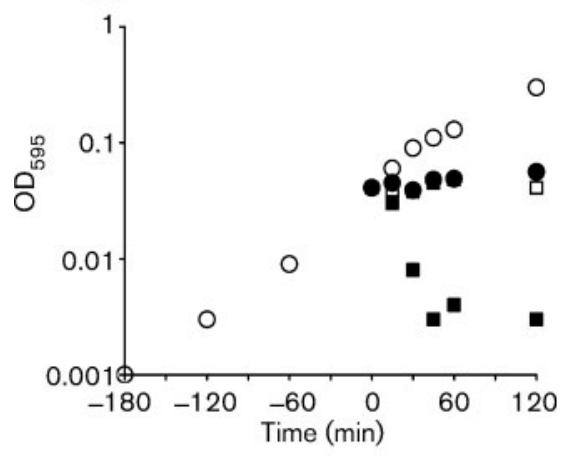

(C)

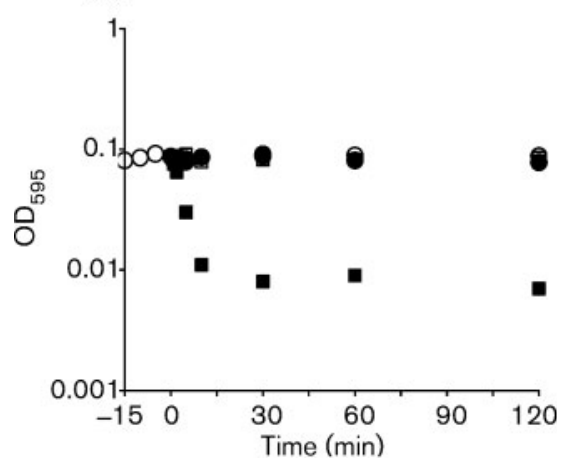

Fig. 2. Comparison of the killing action of corynicin JK and YpkK[Val88-Trp164]. (A) Both recombinant corynicin JK and YpkK [Val88-Trp164] are biologically active against Micrococcus luteus in a spot test assay: a, $10 \mu \mathrm{g}$ purified recombinant corynicin $\mathrm{JK}$; b, $10 \mu \mathrm{g}$ purified recombinant YpkK[Val88-Trp164]; c, $10 \mu \mathrm{g}$ purified recombinant YpkK[Ala28-Ser87]. (B) Corynicin JK and YpkK[Val88-Trp164] inhibit the growth of Lc. lactis T-21 in liquid culture. Lc. lactis T-21 was treated at time 0 with: water (untreated control, $\bigcirc) ; 10$ nM corynicin JK (๑); 60 nM YpkK[Val88-Trp164]

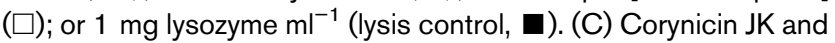
YpkK[Val88-Trp164] do not lyse heat-killed Lc. lactis T-21 in suspension. Heat-killed Lc. lactis T-21 was treated at time 0 with: water (untreated control, $\bigcirc$ ); $10 \mathrm{nM}$ corynicin JK $(\bullet) ; 60 \mathrm{nM}$

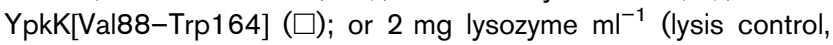
a).

identity, and their potential antimicrobial activity was assessed. Surprisingly, neither showed any detectable antibacterial activity against any of the indicator strains tested. This result could indicate that there is an intimate and customized association between the $\mathrm{N}$ - and C-terminal

segments of these antibiotics that is critical for full antimicrobial activity.

\section{SA-M57, enterococcin V583, corynicin JK and YpkK[Val88-Trp164] kill sensitive bacteria without lysis}

A small number of high molecular mass bacteriocins have been reported that lyse susceptible bacteria. For example, the glycyl-glycine endopeptidase lysostaphin from Staphylococcus simulans hydrolyses the transpeptide bridges of certain staphylococcal cell walls (Schindler \& Schuhardt, 1964; Zygmunt \& Tavormina, 1972), whereas the bacteriocins zoocin A from Streptococcus zooepidemicus (Simmonds et al., 1996, 1997) and stellalysin from Streptococcus constellatus (Heng et al., 2006b) are thought to act in a similar manner against various susceptible streptococci. In addition, the cyclic antimicrobial peptide uberolysin from various Streptococcus uberis strains kills susceptible cells by inducing their lysis (Wirawan et al., 2007). By contrast, we have previously shown that the $21.5 \mathrm{kDa}$ antibiotic protein dysgalacticin kills susceptible cells without lysis (Heng et al., 2006). In the present study we assessed the killing action of SA-M57, enterococcin V583, corynicin JK and YpkK[Val 88-Trp164]. When the proteins were applied to agar-immobilized cell suspensions (Wirawan et al., 2007) of a variety of either live or heatkilled sensitive and non-sensitive indicator strains, we observed no indications of target cell lysis, although further growth of live, sensitive indicators was inhibited as expected. Moreover, addition of either $20 \mathrm{nM}$ corynicin JK or $60 \mathrm{nM} \mathrm{YpkK[Val88-Trp164]} \mathrm{to} \mathrm{a} \mathrm{mid-exponential-}$ phase liquid culture of Lc. lactis T-21 inhibited further growth but did not result in a decrease in optical density (Fig. 2B). Similarly, the optical density of a heat-killed suspension of Lc. lactis T-21 did not change after treatment with either corynicin JK or YpkK[Val 88-Trp164] at the same concentrations (Fig. 2C). In both cases, controls consisting of lysozyme-treated Lc. lactis T-21 showed characteristic loss of optical density, consistent with the murolytic mode of action of this enzyme. Taken together these results indicate that the tested proteins are neither murolytic enzymes nor mediators of lysis induction in sensitive cells; however, the mechanism by which they kill susceptible bacteria, like the basis for their target specificity, remains enigmatic.

\section{Distribution of the genes encoding SA-M57, enterococcin V583 and corynicin JK}

SA-M57 has been previously reported to be widely distributed amongst $M$ type 57 Streptococcus pyogenes, as both the gene (scnM57) and plasmid on which it is carried (pDN571), as well as biologically active SA-M57, were identified in all 37 clinical isolates tested (Heng et al., 2004). In contrast, PCR screening of 33 independent clinical isolates of $C$. jeikeium identified $y p k K$ in just two strains, indicating a relatively restricted distribution of this 
gene in corynebacterial isolates. This finding is surprising given that the plasmid on which $y p k K$ may be carried (pK43-like family) is common among clinical isolates (Tauch et al., 2004). Furthermore, antibacterial activity consistent with corynicin JK could not be detected from $C$. jeikeium $\mathrm{K} 64$ in a modified deferred antagonism test, raising the possibility that $y p k K$ either is not expressed in this strain, or is only expressed under as yet undefined culture conditions.

Using a diagnostic PCR with appropriate primers (Table 1) we have screened 18 independent isolates and found ef 1097 in 10 of 11 strains of Ent. faecalis (including the genome sequence reference strain Ent. faecalis V583: Paulsen et al., 2003) and four of seven strains of Ent. faecium. This result would indicate that, like scnM57, ef1097 is widely distributed amongst natural isolates of enterococci. Moreover, antibacterial activity consistent with enterococcin V583 could also be detected from Ent. faecalis V583 in a modified deferred antagonism test, confirming that the gene is expressed, at least in this strain. In a recent study (Bourgogne et al., 2006), the FsrABC system of enterococci, which is a quorum-sensing regulator of enterococcal virulence (Qin et al., 2000, 2001), was shown to upregulate ef1097 expression (at the level of mRNA) upon entry into stationary phase. The broad distribution of ef1097 in enterococci, coupled with the observation that its expression is tightly regulated together with known virulence factors, may indicate that it is of importance to the producing bacterium and could also indicate that its production is related to enterococcal virulence.

\section{SA-M57, enterococcin V583 and corynicin JK may be part of a broader family of antibiotic proteins from Gram-positive bacteria}

Interestingly, recent interrogation of currently available databases would suggest that at least four further potential family members may also be currently documented as proteins of unknown function: the hypothetical proteins BCZK5154 from Bacillus cereus E33L (accession no. YP_086722; Han et al., 2006), BcerKBAB4DRAFT_0813 from Bacillus weihenstephanensis KBAB4 (accession no. ZP_01187444; A. Lapidus and others, 2006, DOE Joint Genome Institute, unpublished) and BL05338 from Bacillus licheniformis ATCC 14580 (accession no. YP_080680; Rey et al., 2004), as well as the putative 'integral membrane protein' from Lactobacillus plantarum WCFS1 (accession no. NP_786248; Kleerebezem et al., 2004). Although they share little sequence similarity, in silico analysis of these four sequences (not shown) indicates that their translated products are all likely to yield mature proteins of approximately 150 amino acids following cleavage of $\sim 30$ amino acid signal peptides. Moreover, the predicted proteins are composed of two distinct portions, the C-terminal segments of which share similar predicted secondary structure and contain two conserved cysteine residues. Thus, it would seem that the hitherto unrecognized ability of Gram-positive bacteria to produce large proteinaceous antibiotics (bacteriocins) is relatively widely distributed. Indeed, it is tempting to speculate that this family of protein antibiotics may represent the Grampositive equivalent of the colicin family in Gram-negative bacteria (Cascales et al., 2007).

\section{Conclusion}

We have demonstrated that the hypothetical proteins EF1097 and YpkK previously identified in the genome sequences of Ent. faecalis and C. jeikeium (Paulsen et al., 2003; Tauch et al., 2004) are precursors of antimicrobial proteins with similarities to the bacteriocins streptococcin A-M57 (Heng et al., 2004) and dysgalacticin (Heng et al., 2006). We have also shown that dysgalacticin, SA-M57, enterococcin V583 and corynicin JK may form (part of) a family of antibiotic proteins from Gram-positive bacteria that share little sequence similarity whilst maintaining conserved secondary structural elements. Information gained from the variety of recombinant protein segments and chimaeras used in this study indicates that the conserved secondary structure of the C-terminal portion of this family of protein antibiotics may be critical in mediating their killing activity and that target cell death does not involve lysis. Thus, our future studies will be directed at dissecting the basis for their target specificity and defining the mechanism by which the proteins kill susceptible cells.

\section{ACKNOWLEDGEMENTS}

The work reported here was supported in part by grants from the Health Research Council of New Zealand (HRC), The Otago Medical Research Foundation (OMRF) and the University of Otago Research Grants Committee (ORG), and with equipment purchased through funding support from Lottery Health, New Zealand Lottery Grants Board and the Otago School of Medical Sciences.

\section{REFERENCES}

Altschul, S. F., Madden, T. L., Schäffer, A. A., Zhang, J., Zhang, Z., Miller, W. \& Lipman, D. J. (1997). Gapped BLAST and PSI-BLAST: a new generation of protein database search programs. Nucleic Acids Res 25, 3389-3402.

Bonelli, R. R., Wiedemann, I. \& Sahl, H.-G. (2006). Chapter 16: Lantibiotics. In Handbook of Biologically Active Peptides, pp. 97-105. Edited by A. J. Kastin. Burlington: Academic Press.

Bourgogne, A., Hilsenbeck, S. G., Dunny, G. M. \& Murray, B. E. (2006). Comparison of OG1RF and an isogenic $f s r B$ deletion mutant by transcriptional analysis: the Fsr system of Enterococcus faecalis is more than the activator of gelatinase and serine protease. J Bacteriol 188, 2875-2884.

Cascales, E., Buchanan, S. K., Duché, D., Kleanthous, C., Lloubès, R., Postle, K., Riley, M., Slatin, S. \& Cavard, D. (2007). Colicin biology. Microbiol Mol Biol Rev 71, 158-229. 
Chenna, R., Sugawara, H., Koike, T., Lopez, R., Gibson, T. J., Higgins, D. G. \& Thompson, J. D. (2003). Multiple sequence alignment with the CLUSTAL series of programs. Nucleic Acids Res 31, 3497-3500.

Cleveland, J., Montville, T. J., Nes, I. F. \& Chikindas, M. L. (2001). Bacteriocins: safe, natural antimicrobials for food preservation. Int $J$ Food Microbiol 71, 1-20.

Gasteiger, E., Gattiker, A., Hoogland, C., Ivanyi, I., Appel, R. D. \& Bairoch, A. (2003). ExPASy: the proteomics server for in-depth protein knowledge and analysis. Nucleic Acids Res 31, 3784-3788.

Gillor, O., Kirkup, B. C. \& Riley, M. A. (2004). Colicins and microcins: the next generation of antimicrobials. Adv Appl Microbiol 54, 129146.

Han, C. S., Xie, G., Challacombe, J. F., Altherr, M. R., Bhotika, S. S., Brown, N., Bruce, D., Campbell, C. S., Campbell, M. L. \& other authors (2006). Pathogenomic sequence analysis of Bacillus cereus and Bacillus thuringiensis isolates closely related to Bacillus anthracis. $J$ Bacteriol 188, 3382-3390.

Hanahan, D. (1983). Studies on transformation of Escherichia coli with plasmids. J Mol Biol 166, 557-580.

Heng, N. C. K. \& Jack, R. W. (2006). Chapter 13: Microcins. In Handbook of Biologically Active Peptides, pp. 75-82. Edited by A. J. Kastin. Burlington: Academic Press.

Heng, N. C. K., Burtenshaw, G. A., Jack, R. W. \& Tagg, J. R. (2004). Sequence analysis of pDN571, a plasmid encoding novel bacteriocin production in M-type 57 Streptococcus pyogenes. Plasmid 52, 225-229.

Heng, N. C. K., Ragland, N. L., Swe, P. M., Baird, H. J., Inglis, M. A., Tagg, J. R. \& Jack, R. W. (2006a). Dysgalacticin: a novel, plasmidencoded antimicrobial protein (bacteriocin) produced by Streptococcus dysgalactiae subsp. equisimilis. Microbiology 152, 19912001.

Heng, N. C. K., Swe, P. M., Ting, Y.-T., Dufour, M., Baird, H. J., Ragland, N. L., Burtenshaw, G. A., Jack, R. W. \& Tagg, J. R. (2006b). The large antimicrobial proteins (bacteriocins) of streptococci. In International Congress Series \#1289: Conference Proceedings of the 16th Lancefield International Symposium on Streptococci and Streptococcal Diseases, pp. 351-354. Edited by K. S. Sriprakash and others. Amsterdam: Elsevier.

Heng, N. C. K., Wescombe, P. A., Burton, J. P., Jack, R. W. \& Tagg, J. R. (2007). The diversity of bacteriocins in Gram-positive bacteria. In Bacteriocins: Ecology and Evolution, pp. 45-92. Edited by M. A. Riley \& M. A. Chavan. Heidelberg: Springer-Verlag.

Jack, R. W., Wan, J., Gordon, J., Harmark, K., Davidson, B. E., Hillier, A. J., Wettenhall, R. E., Hickey, M. W. \& Coventry, M. J. (1996). Characterization of the chemical and antimicrobial properties of piscicolin 126, a bacteriocin produced by Carnobacterium piscicola JG126. Appl Environ Microbiol 62, 2897-2903.

Jetten, A. M. \& Vogels, G. D. (1972a). Nature and properties of a Staphylococcus epidermidis bacteriocin. J Bacteriol 112, 243-250.

Jetten, A. M. \& Vogels, G. D. (1972b). Mode of action of a Staphylococcus epidermidis bacteriocin. Antimicrob Agents Chemother 2, 456-463.

Jetten, A. M., Vogels, G. D. \& de Windt, F. (1972). Production and purification of a Staphylococcus epidermidis bacteriocin. J Bacteriol 112, 235-242.

Joerger, M. C. \& Klaenhammer, T. R. (1986). Characterization and purification of helveticin $\mathrm{J}$ and evidence for a chromosomally determined bacteriocin produced by Lactobacillus helveticus 481 . J Bacteriol 167, 439-446.

Joerger, M. C. \& Klaenhammer, T. R. (1990). Cloning, expression, and nucleotide sequence of the Lactobacillus helveticus 481 gene encoding the bacteriocin helveticin J. J Bacteriol 172, 6339-6347.
Kirkup, B. C. (2006). Bacteriocins as oral and gastrointestinal antibiotics: theoretical considerations, applied research, and practical applications. Curr Med Chem 13, 3335-3350.

Kleerebezem, M., Boekhorst, J., van Kranenburg, R., Molenaar, D., Kuipers, O. P., Leer, R., Tarchini, R., Peters, S. A., Sandbrink, H. M. \& other authors (2004). Complete genome sequence of Lactobacillus plantarum WCFS1. Proc Natl Acad Sci U S A 100, 1990-1995.

Nes, I. F., Brede, D. A. \& Holo, H. (2006). Chapter 17: The nonlantibiotic heat stable bacteriocins in Gram-positive bacteria. In Handbook of Biologically Active Peptides, pp. 107-114. Edited by A. J. Kastin. Burlington: Academic Press.

Paulsen, I. T., Banerjei, L., Myers, G. S., Nelson, K. E., Seshadri, R., Read, T. D., Fouts, D. E., Eisen, J. A., Gill, S. R. \& other authors (2003). Role of mobile DNA in the evolution of vancomycin-resistant Enterococcus faecalis. Science 299, 2071-2074.

Qin, X., Singh, K. V., Weinstock, G. M. \& Murray, B. E. (2000). Effects of Enterococcus faecalis fsr genes on production of gelatinase and a serine protease and virulence. Infect Immun 68, 2579-2586.

Qin, X., Singh, K. V., Weinstock, G. M. \& Murray, B. E. (2001). Characterization of fsr, a regulator controlling expression of gelatinase and serine protease in Enterococcus faecalis OG1RF. J Bacteriol 183, 3372-3382.

Rey, M. W., Ramaiya, P., Nelson, B. A., Brody-Karpin, S. D., Zaretsky, E. J., Tang, M., Lopez de Leon, A., Xiang, H., Gusti, V. \& other authors (2004). Complete genome sequence of the industrial bacterium Bacillus licheniformis and comparisons with closely related Bacillus species. Genome Biol 5, R77.

Ross, R. P., Morgan, S. \& Hill, C. (2002). Preservation and fermentation: past, present and future. Int J Food Microbiol 79, 3-16.

Rost, B., Yachdav, G. \& Liu, J. (2004). The PredictProtein server. Nucleic Acids Res 32, W321-W326.

Sahl, H.-G. (1994). Staphylococcin 1580 is identical to the lantibiotic epidermin: implications for the nature of bacteriocins from Grampositive bacteria. Appl Environ Microbiol 60, 752-755.

Sambrook, J. \& Russell, D. W. (2001). Molecular Cloning: a Laboratory Manual, 3rd edn. Cold Spring Harbor, NY: Cold Spring Harbor Laboratory.

Schäffer, A. A., Aravind, L., Madden, T. L., Shavirin, S., Spouge, J. L., Wolf, Y. I., Koonin, E. V. \& Altschul, S. F. (2001). Improving the accuracy of PSI-BLAST protein database searches with compositionbased statistics and other refinements. Nucleic Acids Res 29, 2994-3005.

Schindler, C. A. \& Schuhardt, V. T. (1964). Lysostaphin: a new bacteriolytic agent for the Staphylococcus. Proc Natl Acad Sci U S A 51, 414-421.

Simmonds, R. S., Pearson, L., Kennedy, R. C. \& Tagg, J. R. (1996). Mode of action of a lysostaphin-like bacteriolytic agent produced by Streptococcus zooepidemicus 4881. Appl Environ Microbiol 62, 45364541.

Simmonds, R. S., Simpson, W. J. \& Tagg, J. R. (1997). Cloning and sequence analysis of zooA, a Streptococcus zooepidemicus gene encoding a bacteriocin-like inhibitory substance having a domain structure similar to that of lysostaphin. Gene 189, 255-261.

Staubitz, P., Peschel, A., Nieuwenhuizen, W. F., Otto, M., Götz, F., Jung, G. \& Jack, R. W. (2001). Structure-function relationships in the tryptophan-rich, antimicrobial peptide indolicidin. J Pept Sci 7, 552564.

Tagg, J. R. \& Bannister, L. V. (1979). "Fingerprinting" betahaemolytic streptococci by their production of and sensitivity to bacteriocine-like inhibitors. J Med Microbiol 12, 397-411.

Tauch, A., Bischoff, N., Pühler, A. \& Kalinowski, J. (2004). Comparative genomics identified two conserved DNA modules in a 
corynebacterial plasmid family present in clinical isolates of the opportunistic human pathogen Corynebacterium jeikeium. Plasmid 52, 102-118.

Thompson, J. K., Collins, M. A. \& Mercer, W. D. (1996). Characterization of a proteinaceous antimicrobial produced by Lactobacillus helveticus CNRZ450. J Appl Bacteriol 80, 338-348.

Vullo, A. \& Frasconi, P. (2004). Disulfide connectivity prediction using recursive neural networks and evolutionary information. Bioinformatics 20, 653-659.
Wirawan, R. E., Swanson, K. M., Kleffmann, T., Jack, R. W. \& Tagg, J. R. (2007). Uberolysin: a novel cyclic bacteriocin produced by Streptococcus uberis. Microbiology 153, 1619-1630.

Zygmunt, W. A. \& Tavormina, P. A. (1972). Lysostaphin: model for specific enzymatic approach to infectious disease. Prog Drug Res 16, 309-333.

Edited by: D. M. Gordon 